\title{
OPEN Head movement differs for positive and negative emotions in video recordings of sitting individuals
}

\begin{abstract}
Maciej Behnke ${ }^{1 \bowtie}$, Nadia Bianchi-Berthouze ${ }^{2}$ \& Lukasz D. Kaczmarek ${ }^{1}$
Individuals tend to approach positive stimuli and avoid negative stimuli. Furthermore, emotions influence whether individuals freeze or move more. These two kinds of motivated behavior refer to the approach/avoidance behavior and behavioral freezing/activation. Previous studies examined (e.g., using forced platforms) whether individuals' behavior depends on stimulus' valence; however, the results were mixed. Thus, we aimed to test whether emotions' effects on spontaneous wholebody behavior of standing individuals also occur in the seated position. We used a computer vision method to measure the head sway in video recordings that offers ease of use, replicability, and unobtrusiveness for the seated research participant. We analyzed behavior recorded in the laboratory during emotion manipulations across five studies totaling 932 participants. We observed that individuals leaned more forward and moved more when watching positive stimuli than when watching negative stimuli. However, individuals did not behave differently when watching positive or negative stimuli than in the neutral condition. Our results indicate that head movements extracted from seated individuals' video recordings can be useful in detecting robust differences in emotional behavior (positive vs. negative emotions).
\end{abstract}

Individuals tend to lean and move towards positively valenced stimuli (approach behavior) ${ }^{1,2}$, and lean and move away from negatively valenced stimuli (avoidance behavior) ${ }^{3-7}$. Studying body sway has contributed to several applied contexts. For instance, body sway in response to affective stimuli was used to study posttraumatic stress ${ }^{6}$, aggression $^{8}$, social threat ${ }^{9}$, and Parkinson's disease ${ }^{10}$. Most previous studies focused on standing participants. However, relatively less is known whether behavior of seated participants reveals the same emotional responses. Thus, our aim was to examine whether effects of valence on body sway also show up in head movement among seated participants. We focused on leaning forward vs. away and freezing vs. activation, dependent on whether individuals face positive (leaning forward and activation) or negative (leaning backward and freeze) stimuli. Moreover, whereas most previous studies used force-platforms $s^{3,4,11,12}$, we focused on video recordings to capitalize on more recent data analysis methods.

Body sway is a component of emotional behavior and is organized by its direction and intensity ${ }^{13}$. For direction, the biphasic approach to emotions suggests that emotion is organized around two motivational systems: approach oriented or appetitive and avoidance oriented or defensive ${ }^{13}$. For instance, individuals display avoidance behavior to pictures of mutilated bodies ${ }^{3}$, dangerous animals ${ }^{4}$, and guns ${ }^{1}$. In contrast, individuals display approach behavior to pictures of smiling individuals ${ }^{2}$, attractive individuals, beautiful landscapes, and delicious food $^{1}$. Furthermore, for emotional behavior intensity, individuals decrease their body mobility facing negatively evaluated stimuli-response operationalized as behavioral freezing ${ }^{14,15}$. Freezing in response to aversive stimuli results from the adaptation to avoid threats ${ }^{16,17}$. Individuals reduce body movement when facing unpleasant stimuli, including social threat ${ }^{9}$, mutilation images ${ }^{11,16}$, anticipating electrical shock ${ }^{18}$, standing at height ${ }^{19}$, and recalling sad memories ${ }^{20}$. In contrast, individuals facing pleasant stimuli move more ${ }^{21-24}$. Activation in response to positive stimuli reflects the readiness to explore, play, or loosen up and decrease tension ${ }^{5,25}$. For instance, individuals activate and increase body movement when facing erotic scenes ${ }^{21,22,24}$, amusing traffic situations ${ }^{23}$, or watching pictures of offspring ${ }^{22}$.

Although most studies support the difference between negative and positive emotions, some studies did not find a differential influence of positive and negative emotions on behavior. For instance, some studies revealed no differences between positive and neutral conditions $s^{4,9,12,24}$ and between negative and neutral conditions ${ }^{3,11,24}$ in their influence on approach/avoidance behavior. However, in some, there was a significant difference between positive vs. negative emotions $s^{9,24}$. Moreover, for behavioral freezing/activation, some research indicated no 


\begin{tabular}{|c|c|c|c|c|c|c|c|}
\hline \multirow[b]{2}{*}{ Study number } & \multicolumn{3}{|c|}{ Sample characteristics } & \multicolumn{4}{|l|}{ Study characteristics } \\
\hline & Size (\% female) & Mean age (SD) & Participant pool (ethnicity) & Study procedure & Method & Originally elicited emotions & Design \\
\hline Study 1 & $149(53)$ & $21.40(2.67)$ & Undergraduates (Caucasian) & $\begin{array}{l}\text { Baseline ( } 5 \mathrm{~min}) \text {, series of six } \\
\text { videos (all positive, all nega- } \\
\text { tive, or all neutral) }(12 \mathrm{~min}) \\
\text { ultimatum game }\end{array}$ & Film clips & $\mathrm{PE}, \mathrm{NE}$, and $\mathrm{NC}$ & Between \\
\hline Study 2 & $214(49)$ & $22.42(2.68)$ & Romantic couples (Caucasian) & $\begin{array}{l}\text { Baseline ( } 5 \mathrm{~min} \text { ), three rounds } \\
\text { of emotional film clips, and } \\
\text { responses to partner success } \\
\text { (capitalization) }\end{array}$ & Film clips & $\mathrm{PE}, \mathrm{NE}$, and $\mathrm{NC}$ & Between \\
\hline Study 3 & $146(70)$ & $21.91(2.45)$ & Undergraduates (Caucasian) & $\begin{array}{l}\text { Baseline }(5 \mathrm{~min}) \text {, speech prepa- } \\
\text { ration }(30 \mathrm{~s}) \text {, pictures presenta- } \\
\text { tion }(3 \mathrm{~min}) \text {, recovery }\end{array}$ & Pictures & $\begin{array}{l}\text { High-approach PE, low- } \\
\text { approach PE, and NC }\end{array}$ & Between \\
\hline Study 4 & $189(45)$ & $21.83(2.32)$ & Undergraduates (Caucasian) & $\begin{array}{l}\text { Baseline (5 min), pictures } \\
\text { presentation (3 min), speech } \\
\text { preparation (3 min), recovery }\end{array}$ & Pictures & $\begin{array}{l}\text { High-approach PE, low- } \\
\text { approach PE, and NC }\end{array}$ & Between \\
\hline Study 5 & $233(0)$ & $23.69(3.53)$ & Gamers (Caucasian) & $\begin{array}{l}\text { Baseline ( } 5 \mathrm{~min} \text { ), five rounds } \\
\text { of emotional film clip (random } \\
\text { order; } 2 \mathrm{~min}) \text {, video-game } \\
\text { match }(8 \mathrm{~min}) \text {, recovery } \\
(2 \mathrm{~min})\end{array}$ & Film clips & $\begin{array}{l}\text { PE (amusement, enthusiasm), } \\
\text { NE (anger, sadness), and NC }\end{array}$ & Within \\
\hline
\end{tabular}

Table 1. Overview of studies characteristics. $P E$ positive emotions, $N E$ negative emotions, $N C$ neutral condition.

differences between positive and neutral conditions $s^{11,12,24}$, between negative and neutral conditions $s^{3,6,11,24}$, and between negative and positive conditions $s^{11,24}$. These mixed findings indicate that the relationship between emotional behavior and valence is complex and easier to detect between extreme values (positive vs negative) than between extreme and middle values (e.g., positive vs. neutral) ${ }^{23,24,26}$.

The majority of research on body sway tested standing individuals (including unipedal stance) where shifts in center of pressure are most pronounced in the anterior-posterior direction during bipedal stance ${ }^{9}$ or during unipedal stance ${ }^{11}$. The research on body sway in a seated position is sparse $e^{6,27}$. Advancing methods of testing body sway in sitting individuals is important because individuals spend increasingly more time sitting, e.g., at work and leisure time ${ }^{28}$. Moreover, an increasing number of research focuses on new forms of activities that individuals perform while sitting (e.g., esports performance ${ }^{29}$ ). Thus, testing whether emotions' effects on standing individuals' behavior also occur in the more restricted seated position increases ecological validity and evidence diversity in the body sway research.

Furthermore, we focused on head movements as a commonly available movement index that can be extracted from video recordings. The head position relative to a stimulus is considered a critical output of seated postural responses ${ }^{6}$. Video recordings allow assessing the amount of spontaneous head and body sway of standing individuals with a reliability comparable to stabilometric force platform ${ }^{24}$. The advantage of using data extracted from video recordings comes from its low-cost and ease of use. Video data can be easily collected in laboratory experiments or ambulatory settings, including real-life scenarios.

In the present study, we reanalyzed five data sets totaling 931 participants (Table 1). We used video recordings from previous studies that were focused on the functions of positive emotions and cardiovascular responses ${ }^{30-33}$. We focused on dimensional conceptualizations of emotion (positive/negative) to address research investigating emotional experiences and their effects upon motor activity ${ }^{34}$. Thus, we focused on responses to positive, negative, and neutral stimuli. Moreover, we focused on two aspects of spontaneous emotional behaviors: direction (approach and avoidance behavior) and intensity (behavioral freezing/activation). The approach behavior is indicated by leaning forward and towards the stimulus, whereas avoidance behavior as moving away and reclining backward ${ }^{35}$. Behavioral freezing is defined as the reduction of body movement, whereas behavioral activation as an increase of body movement. Of note, these two features of behavior, i.e., direction and intensity, are relatively independent from each other. For instance, individuals facing a threat could recline backward and reduce their movement (avoidance and freezing behavior). In response to a neutral stimulus, individuals might neither recline nor lean forward but perform spontaneous nondirectional movements. Finally, to the positive stimuli, individuals might lean forward and perform more nondirectional movements. Building upon the previous research ${ }^{1,9,21,22,24}$, we expected that negative stimuli would influence individuals to move backward and move less (avoidance and freezing), whereas positive stimuli would influence individuals to lean forward and move more (approach and activation).

\section{Results}

We accounted for five studies, presenting behavioral reactivity to 24 affective stimuli obtained from 931 participants with age ranging from 18 to 35 (M 22.37, SD 2.93). Of participants, 372 (40\%) were female. The most frequently studied valence category was positive emotions (1676 reactions; $39.5 \%$ ), then negative emotions (1444 reactions; $34.0 \%$ ), and neutral conditions (1096 reactions; $25.80 \%$ ). The regression models fit data well for approach/avoidance behavior, $P P p=0.480,95 \%$ CI $[-6.368,7.436]$, and for freezing/activation behavior $P P p=0.471,95 \%$ CI $[-7.429,7.167]$. 


\section{Approach/Avoidance}

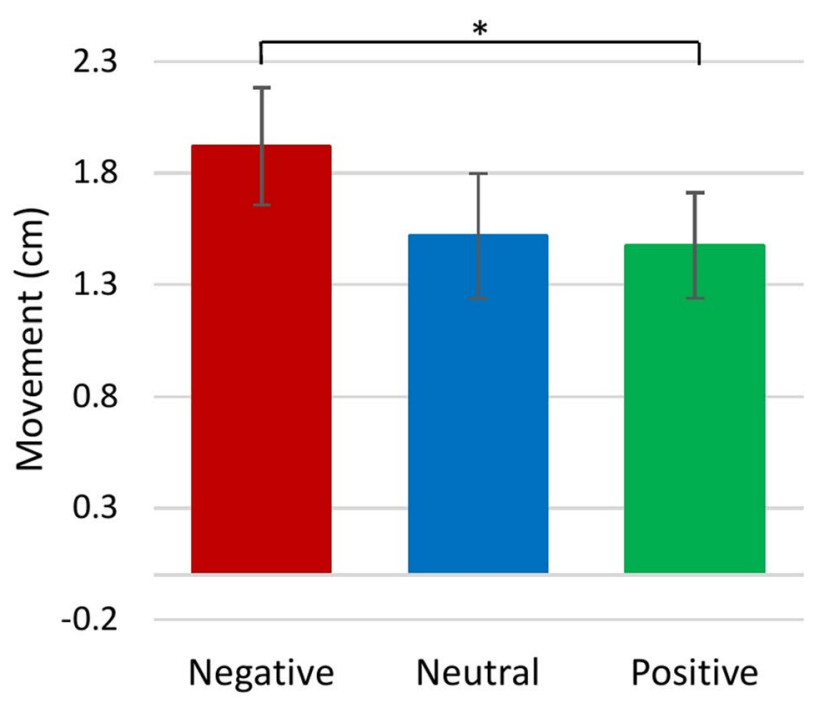

\section{Freezing/Activation}

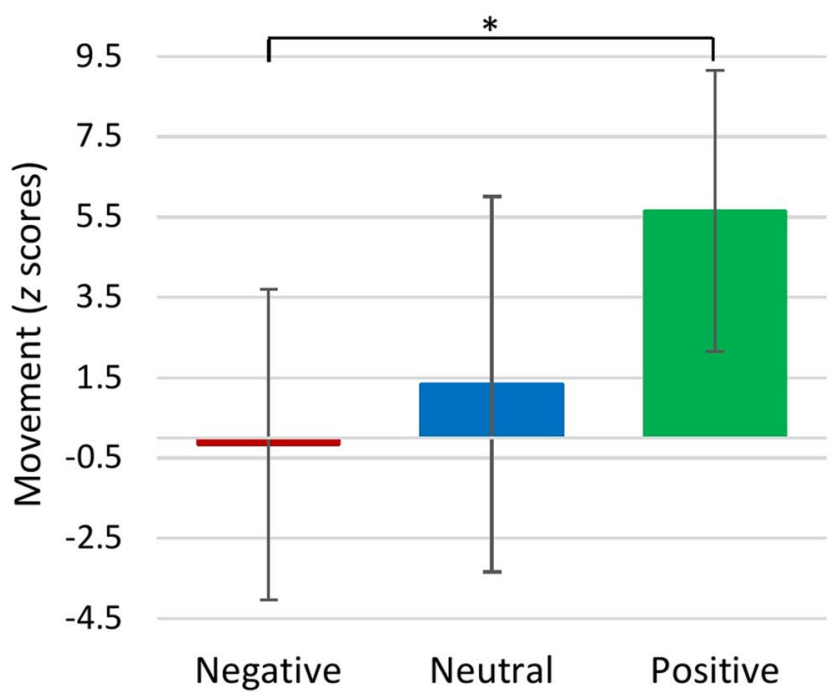

Figure 1. Emotional behavior reactivity for neutral, negative, and positive stimuli from baseline. Approach/ Avoidance is expressed in centimeters as the change of the distance between head and camera; Freezing/ Activation is expressed in $z$ scores as the change of the total body sway; Error bars represent $95 \%$ confidence intervals of the means; Asterisks indicate significant differences between stimulus categories $\left({ }^{*} p<0.05\right)$.

Approach/avoidance behavior. We found that the approach/avoidance behavior differs between negative and positive stimuli, $\Delta \beta=-0.050,95 \%$ CI $[0.008,0.093], p=0.011$. Individuals leaned backward more while watching negative stimuli $(M-1.92 \mathrm{~cm}, S D 4.06 \mathrm{~cm})$ than while watching positive stimuli $(M-1.47 \mathrm{~cm}, S D$ $4.07 \mathrm{~cm})$ (Fig. 1). However, approach/avoidance behavior to neutral stimuli $(M-1.52 \mathrm{~cm}, S D 4.10 \mathrm{~cm})$ did not differ from the behavior to negative stimuli, $\beta=-0.045,95 \%$ CI $[-0.091,0.002], p=0.030$, and positive stimuli, $\beta=0.006,95 \%$ CI $[-0.037,0.051], p=0.403$.

Behavioral freezing/activation. We found that the behavioral freezing/activation differed between negative and positive stimuli, $\Delta \beta=-0.041,95 \%$ CI [0.003, 0.079], $p=0.016$. Individuals moved less while watching negative stimuli $(M-0.17, S D$ 67.65) than while watching positive stimuli ( $M$ 5.66, $S D$ 66.15) (Fig. 1$)$. However, behavioral freezing/activation to neutral stimuli $(M 1.34, S D 72.56)$ did not differ from negative stimuli, $\beta=-0.010,95 \%$ CI $[-0.050,0.034], p=0.327$, and positive emotions $\beta=0.031,95 \%$ CI $[-0.012,0.071], p=0.068$.

\section{Discussion}

We demonstrated how emotions impact the spontaneous head sway in seated individuals. We observed differences between responses to positive and negative stimuli. First, the head distance was shorter relative to positive stimuli than to negative stimuli. These findings are in line with the majority of previous studies ${ }^{1,9,24}$. It supports the biphasic approach to emotions, which suggests that emotions are organized around two motivational systems: approach oriented or appetitive and avoidance oriented or defensive systems ${ }^{13}$. Second, individuals moved less while facing negatively evaluated stimuli relative to positively evaluated stimuli. Again, this finding is consistent with the majority of the previous studies ${ }^{9,16,21-23}$. It supports that the emotional behavior is organized by its direction as well as intensity ${ }^{13}$. Thus, our findings provide evidence that corroborates previous research using relatively novel methods ${ }^{9,16,21-24}$. However, the observed effects should be interpreted as subtle as the effect sizes were small.

We did not find the differences between positive or negative stimuli relative to neutral stimuli. Some previous studies also showed no differences for approach/avoidance behavior and freezing/activation behavior $3,4,6,9,11,12,24$. This, again, indicates that it is easier to differentiate between extreme values than between extreme and intermediate values ${ }^{23,24,26}$.

Seeking to advance understanding of the emotional influence on complex human behavior, we used two novel methodological approaches. First, we used head movements as a reliable and ecologically valid index of the amount of spontaneous body sway during emotion elicitation in standing individuals ${ }^{24}$. We aimed to examine previous findings derived from stabilometric force platforms with using head movements as a commonly available, low-cost movement index that can be determined from the video recordings. We observed that the head measures were sensitive to experimental manipulation, as indicated by differences between positive and negative emotions. In Study 5, we included leg movements as an additional measure of behavioral freezing/activation. Due to our knowledge, it was the first attempt to account for lower limb spontaneous mobility as the measure of emotional behavior. While head movement might be restricted by chair headrest, armrest, or attached additional apparatus (e.g., electromyography or eye-tracking devices), the leg activity might be the easily available index of the behavioral reactivity. 
Second, studies within the whole-body movement paradigm mainly reported data of participants standing on a force platform, whereas we focused on the body sway of seated participants. During quiet upright standing, the human body exhibits a small amount of spontaneous postural fluctuation, which can even be reduced in response to aversive stimuli. The reduction occurs because of contraction or stiffening of the muscles around the ankle joint ${ }^{11,16,17}$. We argue that the stiffening is not limited to ankle joints and would also occur in the upper body (e.g., contraction trapezius muscle) ${ }^{36}$, and should be visible in the seated postural responses. Studies accounting for muscle activity and spontaneous movements will be necessary to confirm this hypothesis. Since adults spend more than half of their day sedentary ${ }^{28}$, further studying seated postural responses would ecologically valid.

The study has several limitations. First, based on the previous study on standing individuals ${ }^{24}$, we assumed that seated individuals' video recordings would suffice to determine the influence of valence on emotional behavior. However, seated individuals are in a more restricted position than standing individuals and have fewer degrees of freedom in motion. Participants in our studies sat on the chair with a backrest that might limit their anterior-posterior body sway and an armrest that might limit their medial-lateral body sway. Thus, the subtle effect of emotions on spontaneous whole-body behavior might not be detectable while measured in a restricted body position. For instance, researchers found the effects of emotions on spontaneous behavior only in unipedal stance, but not bipedal stance, which indicates that the degrees of freedom of spontaneous motion matters ${ }^{11}$. This might explain why we found differences between the valence dimension's extremes-positive and negative emotions, but not from the neutral condition. More studies that compare whole-body standing movement and seated postural responses might support this hypothesis. Future studies may also use an experimental setup with the sitting ball without arm- and backrests to allow for additional movements while sitting. Second, we based our conclusions on data from video recordings instead of using the force platform that is the state-of-the-art method in behavioral literature. Future studies may validate the initial findings on the comparability of both methods ${ }^{24}$. Third, in our studies, we did not control for eye movements that would inform whether individuals focused on specific parts of the screen while watching the positive and negative stimuli. For instance, head movements might be stronger for stimuli where individuals had to switch their focus between different parts of the scene, i.e., to understand the social interaction between several individuals. In contrast, some negative stimuli might produce a stronger focus on one part of the screen (e.g., a dangerous animal). Thus, the complexity of the stimuli might interact with the effects of valence. Future studies might account for this limitation by controlling for eye movements or by selecting positive and negative stimuli that produce similar eye movements. Fourth, we compared positive, negative emotions, and neutral conditions, whereas the discrete emotion approach could yield more insight. Recent work has demonstrated that discrete emotions often differentially impact cognition and physiology even when of the same valence ${ }^{35,37,38}$. Furthermore, we used multiple film clips to elicit single emotion, which provides additional variation in the manipulation strength. However, this approach also generalizes the impact of emotional valence and limits the effect of using specific stimuli. Researchers might use our approach to re-examine findings from other laboratory experiments on discrete emotions, in which behavioral reactivity was not the main focus. Given that behavioral reactivity (with the exemption of facial expressions) gained relatively low popularity in affective science, reexaminations of existing data may result in an effective way to increase the number of examined emotion.

This study's strength is in the use of a novel method of movement analysis with a large number of participants. We evidenced that the analysis of head sway among participants in a seated position can reflect affective influences. As recording videos of sitting participants is affordable and easy, studies within the field of affective science might increasingly use this method to expand the scope of emotional behavior analysis.

\section{Methods}

Participants. Participants' characteristics are presented in Table 1. All studies were approved by and performed in accordance with guidelines and regulations of the Institutional Ethics Committee at Faculty of Psychology and Cognitive Science, Adam Mickiewicz University. Participants in our studies provided written informed consent and received cinema tickets for their involvement. The data for this investigation were collected from November 2016 to March 2019 in Poznan, Poland.

Procedure. All five experiments began with a 5-min resting baseline. Participants were asked to wait for five minutes without doing any unnecessary actions. During the experiments, we elicited emotions (Table 1), presenting affective pictures or film clips. Unlike previous studies that used the head movement of standing individuals as an index of emotional behavior ${ }^{24,26}$, participants in our study sat on a chair with the back and armrests throughout all studies.

Affective stimuli. Films. We used stimuli from the emotion-eliciting video clip databases to elicit emotions, with prior evidence of reliability and validity ${ }^{39-42}$. Each clip lasted two minutes. Within the sessions, clips were presented in a counterbalanced order. Table 1 presents which films were used to elicit emotions in the studies.

For positive emotions, we used validated movie clips: (1) A fish called Wanda (Unexpectedly, the owners of the house get into the house and discover Archie dancing naked); (2) The visitors (The visitors destroy the postman's car); (3) When Harry met Sally (Sally fakes an orgasm in the restaurant); (4) The Dead Poets Society (Students climb on their desks to manifest their solidarity with their teacher); (5) Life is beautiful (In a prisoner's camp, a father and a boy talk to the mother using a loudspeaker); (6) Benny \& Joone (Benny plays the fool in a coffee shop); and (7) Summer Olympic Games (montage of moments showing athletes successful performance and their joyful reactions). We used films 1-6 in Study 1, films 1-3 in Study 2, and film 1 and 7 in Study 5. 


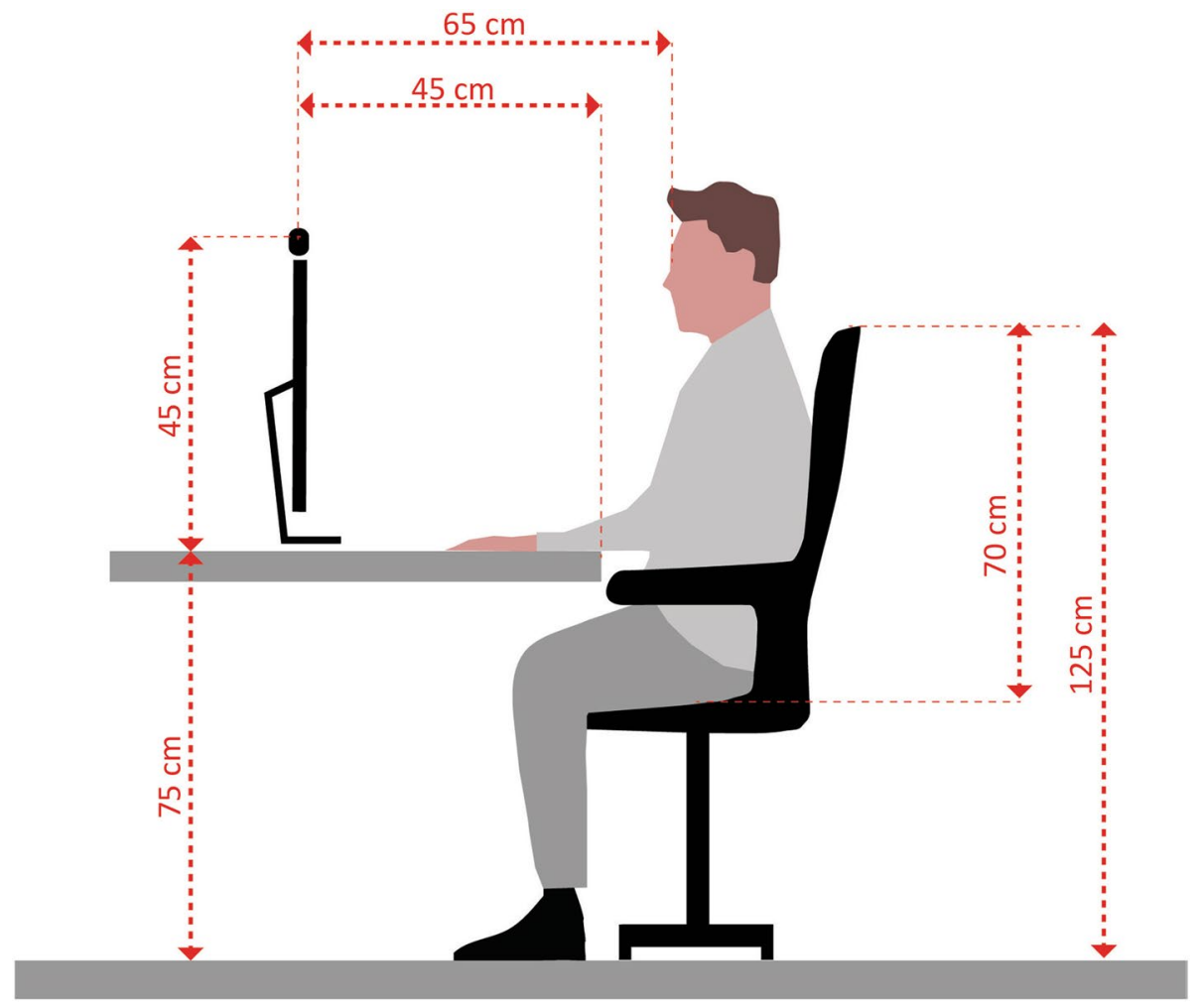

Figure 2. Schematic figure of the experimental setup. This figure was created by Katarzyna Janicka. The copyright of the figure is held by Katarzyna Janicka.

For negative emotions, we used validated movie clips (1) American History X (A neo-nazi smashes a Black man's head on the curb and killing him); (2) Man bites dog (A hitman pulls out a gun, yelling at an old lady); (3) In the name of the father (Scene of interrogation); (4) The Blair Witch Project (the characters die in an abandoned house); (5) Seven (the police find the decaying corpse); (6) Dangerous minds (the teacher tells the class that one of their classmates is dead); and (7) The Champ (boy cries at the death of his father). We used films 1-6 in Study 1, films 1-3 in Study 2, and film 1 \& 7 in Study 5.

For neutral conditions, we used validated movie clips: (1) Blue 1 (A man clears out the drawers of his desk, or a woman walks in an alley); (2) Blue 2 (A woman goes up on an escalator, carrying a box); (3) Blue 3 (A person passes a piece of aluminum foil through the window of a car); (4) Emperor 1 (The Emperor talks with his teacher); (5) Emperor 2 (scenes from the city life); (6) The lover (the protagonist walks around the city); (7) Twin Peaks: Fire Walk with Me (the character sweeps the floor in the bar). We used films 1-5 \& 7 in Study 1, films 1, $4 \& 5$ in Study 2, and film 2 in Study 5.

Pictures. In Study 3 and 4, we used validated pictures ${ }^{31}$ from the Nencki Affective Pictures System ${ }^{43}$. We selected three groups of items: high-approach positive affect (Faces340; Landscapes008, L023, L100, L110, L117, L,140, L149, Objects078, O081, O096, O183, O254, O291, O323, People108, P173, P189), low-approach positive affect (Animals099, A153, Faces076, F113, F179, F228, F232, F234, F238, F330, F332, F337, F344, F347, F353, F358, Objects192, O260), and neutral (Faces157, F166, F167, F309, F312, Landscapes012, L016, L024, L056, L061, L067, L076, L079, Objects112, O204, O210, O310, O314). In Study 3 \& 4 we used the same set of pictures.

Measures. Apparatus. We recorded the head movements of each participant continuously using an HD camera mounted on the top of the PC screen. The distance from the camera to participants' head was approximately $65 \mathrm{~cm}$ (Fig. 2). The video data were analyzed using facial expression analysis software Quantum Sense

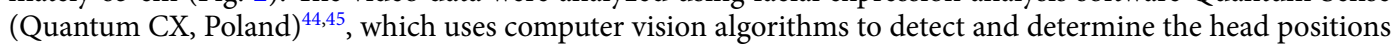
in a three-dimensional space for each frame. Data was recorded with the sampling rate of 15 FPS in Study 1 and Study 2, 10 FPS in Study 3 and Study 4, and 24 FPS in Study 5. We also included leg movements in Study 5. We used four accelerometers (wGT3X-BT, Actigraph, USA) attached to left and right knee and left and right ankle to record physical activity continuously and unobtrusively.

Avoidance/approach behavior. We measured the head position along the anterior-posterior axis, as the distance of the head from the camera. We calculated the mean distance of the head from the camera from two moments in our studies: (1) the last two minutes of resting baseline to account for the part of the baseline that was the most proximal to the study, and (2) the last $2 \mathrm{~min}$ of emotion manipulation. To operationalize changes 
of avoidance/approach behavior, we used reactivity scores corrected for the baseline levels; thus, we subtracted the levels of the last $120 \mathrm{~s}$ of baseline from the level of the last $120 \mathrm{~s}$ of the emotion manipulation. We did this due to differential lengths of presentation of the pictures $(3 \mathrm{~min})$ and film clips $(2 \mathrm{~min})$ and to account for the part of manipulation that is usually more affected by emotions elicitation ${ }^{40}$. This is a validated approach in affective sciences in studies that compare responses to two different stimuli of different durations ${ }^{46,47}$. The head sway in the anterior direction (the positive difference between baseline and affective stimuli) indicates approach behavior, whereas the head sway in the posterior direction (the negative difference between baseline and affective stimuli) indicates avoidance behavior.

Behavioral freezing/activation. We measured behavioral freezing/activation with the total movement of head sway. First, we calculated the total movement of the head in $X, Y, Z$ axis, based on the difference in head position in consecutive video frames. Second, we summed up the magnitude of head sway from two moments in our studies: last $2 \mathrm{~min}$ of baseline and last two minutes of emotion elicitation. To operationalize behavioral change of head sway to emotional stimuli, we used reactivity scores corrected for baseline levels. The decreased total body sway (the negative difference between baseline and affective stimuli) indicates behavioral freezing, whereas the increased total head sway (the positive difference between baseline and affective stimuli) indicates behavioral activation. In Study 5, we also calculated the magnitude of legs movement as the sum of all four joints sways in $X, Y, Z$-axis. The internal reliability for four joints movements was satisfactory, $\alpha=0.84$. To test the impact of emotions on behavioral freezing/activation collected from two movement sources (head and legs), we converted the data from each source of behavioral activity into the $z$-scores, and we merged them into a single variable.

Analytical strategy. To summarize data from our multiple studies showing how emotions influence behavioral reactivity, we used three-level regression models using mPlus $8.0^{48}$. We ran the three-level regression models to account for dependency within-person (level 2) and within a study (level 3). Furthermore, we used three-level regression models to determine global trends across studies to account for dependency between the studies (e.g., studies conducted by the same laboratory, by the same team of researchers). We regressed the approach/avoidance behavior and freezing/activation behavior on the experimental condition (positive, negative, and neutral stimuli). We dummy-coded the experimental conditions such that significant differences in the model accounted for differences relative to the neutral condition. Furthermore, the behavioral reactivity to emotion category (positive emotions vs. negative emotions) was considered as significantly different if the $95 \%$ confidence intervals of the difference between regression coefficients in subgroups did not include zero. We ran the analysis with the Bayesian correction estimator (Bayes), and we used the Bayesian Posterior Predictive $(P P p)$ to evaluate model fit. A well-fitting model should have a $P P p$ value around 0.50 in combination with symmetric $95 \%$ credibility intervals centering on zero ${ }^{49,50}$. We removed outliers above z-scores higher than $3.29^{51}$, resulting in 721 data points $(4.90 \%)$ removed from the initial data sample.

\section{Data availability}

The datasets generated during the current study are available from the corresponding author upon request. All data analyzed during this study are included in this published article (Supplementary Information file).

Received: 17 December 2020; Accepted: 22 March 2021

Published online: 01 April 2021

\section{References}

1. Eerland, A., Guadalupe, T. M., Franken, I. H. \& Zwaan, R. A. Posture as index for approach-avoidance behavior. PLoS ONE https:// doi.org/10.1371/journal.pone.0031291 (2012).

2. Gea, J. et al. Viewing pain and happy faces elicited similar changes in postural body sway. PLoS ONE https://doi.org/10.1371/2Fjou rnal.pone.0104381 (2014).

3. Hagenaars, M. A., Stins, J. F. \& Roelofs, K. Aversive life events enhance human freezing responses. J. Exp. Psychol. Gen. 141, 98-105 (2012).

4. Hillman, C. H., Rosengren, K. S. \& Smith, D. P. Emotion and motivated behavior: postural adjustments to affective picture viewing. Biol. Psychol. 66, 51-62. https://doi.org/10.1016/j.biopsycho.2003.07.005 (2004).

5. Frijda, N. H. The laws of emotion. Am. Psychol. 43, 349-358. https://doi.org/10.1037/0003-066X.43.5.349 (1988).

6. Woodward, S. H. et al. Seated movement indexes emotion and its regulation in posttraumatic stress disorder. Psychophysiology $\mathbf{5 2}$, 679-686. https://doi.org/10.1111/psyp.12386 (2015).

7. Gable, P. \& Harmon-Jones, E. The motivational dimensional model of affect: Implications for breadth of attention, memory, and cognitive categorization. Cogn. Emot. 24, 322-337. https://doi.org/10.1080/02699930903378305 (2010).

8. Santos, M. F. et al. Hands up! Atypical defensive reactions in heavy players of violent video games when exposed to gun-attack pictures. Front. Psychol. 10, 191. https://doi.org/10.3389/fpsyg.2019.00191 (2019).

9. Roelofs, K., Hagenaars, M. A. \& Stins, J. F. Facing freeze: Social threat induces bodily freeze in humans. Psychol. Sci. 21, 1575-1581. https://doi.org/10.1177/2F0956797610384746 (2010).

10. Pasman, E. P., Murnaghan, C. D., Bloem, B. R. \& Carpenter, M. G. Balance problems with Parkinson's disease: Are they anxietydependent?. Neuroscience 177, 283-291. https://doi.org/10.1016/j.neuroscience.2010.12.050 (2011).

11. Stins, J. F. \& Beek, P. J. Effects of affective picture viewing on postural control. BMC Neurosci. 8, 83. https://doi.org/10.1186/14712202-8-83 (2007).

12. Mouras, H., Lelard, T., Ahmaidi, S., Godefroy, O. \& Krystkowiak, P. Freezing behavior as a response to sexual visual stimuli as demonstrated by posturography. PLoS ONE https://doi.org/10.1371/2Fjournal.pone.0127097 (2015).

13. Bradley, M. M., \& Lang, P. J. Emotion and motivation. In Handbook of Psychophysiology (eds Cacioppo, J. T., Tassinary, L. G., \& Berntson, G. G.) 581-607. (Cambridge University Press, 2007). https://doi.org/10.1017/CBO9780511546396.025.

14. Lang, P. J. \& Bradley, M. M. Appetitive and defensive motivation: Goal-directed or goal-determined?. Emot. Rev. 5, $230-234$. https://doi.org/10.1177/2F1754073913477511 (2013). 
15. Blanchard, R. J., Flannelly, K. J. \& Blanchard, D. C. Defensive behaviors of laboratory and wild Rattus norvegicus. J. Comp. Psychol. 100, 101. https://doi.org/10.1037/0735-7036.100.2.101 (1986).

16. Azevedo, T. M. et al. A freezing-like posture to pictures of mutilation. Psychophysiology 42, 255-260. https://doi.org/10.1111/j. 1469-8986.2005.00287.x (2005).

17. Facchinetti, L. D., Imbiriba, L. A., Azevedo, T. M., Vargas, C. D. \& Volchan, E. Postural modulation induced by pictures depicting prosocial or dangerous contexts. Neurosci. Lett. 410, 52-56. https://doi.org/10.1016/j.neulet.2006.09.063 (2006).

18. Hashemi, M. M. et al. Neural dynamics of shooting decisions and the switch from freeze to fight. Sci. Rep. 9, 4240. https://doi.org/ 10.1038/s41598-019-40917-8 (2019).

19. Cleworth, T. W. \& Carpenter, M. G. Postural threat influences conscious perception of postural sway. Neurosci. Lett. 620, 127-131. https://doi.org/10.1016/j.neulet.2016.03.032 (2016).

20. Fawver, B., Hass, C. J., Park, K. D. \& Janelle, C. M. Autobiographically recalled emotional states impact forward gait initiation as a function of motivational direction. Emotion 14, 1125-1136. https://doi.org/10.1037/a0037597 (2014).

21. Naugle, K. M., Hass, C. J., Joyner, J., Coombes, S. A. \& Janelle, C. M. Emotional state affects the initiation of forward gait. Emotion 11, 267-277. https://doi.org/10.1037/a0022577 (2011).

22. Stins, J. F., van Gelder, L. M., Oudenhoven, L. M. \& Beek, P. J. Biomechanical organization of gait initiation depends on the timing of affective processing. Gait Posture. 41, 159-163. https://doi.org/10.1016/j.gaitpost.2014.09.020 (2015).

23. Hagenaars, M. A., Roelofs, K. \& Stins, J. F. Human freezing in response to affective films. Anxiety Stress Copin. 27, 27-37. https:// doi.org/10.1080/10615806.2013.809420 (2014).

24. Ciria, L. F. et al. Head movement measurement: An alternative method for posturography studies. Gait Posture. 52, 100-106. https://doi.org/10.1016/j.gaitpost.2016.11.020 (2017).

25. Fredrickson, B. L. What good are positive emotions?. Rev. Gen. Psychol. 2, 300-319. https://doi.org/10.1037/2F1089-2680.2.3.300 (1998).

26. Kosonogov, V. et al. Head motion elicited by viewing affective pictures as measured by a new LED-based technique. Multisens. Res. 32, 575-588. https://doi.org/10.1163/22134808-20191363 (2019).

27. Shibata, T., Michishita, A. \& Bianchi-Berthouze N. Analysis and modelling of affective Japanese sitting postures by Japanese and British observers, In Humaine Association Conference on Affective Computing and Intelligent Interaction, 91-96, https://doi. org/https://doi.org/10.1109/ACII.2013.22 (2013).

28. Matthews, C. E. et al. Amount of time spent in sedentary behaviors in the United States, 2003-2004. Am. J. Epidemiol. 167, 875-881. https://doi.org/10.1093/aje/kwm390 (2008).

29. Behnke, M., Kosakowski, M. \& Kaczmarek, L. D. Social challenge and threat predict performance and cardiovascular responses during competitive video gaming. Psychol. Sport Exerc. 46, 101584. https://doi.org/10.1016/j.psychsport.2019.101584 (2020).

30. Behnke, M., Gross, J.J. \& Kaczmarek L.D. The role of emotions in esports performance. Emotion. https://doi.org/10.1037/emo00 $00903(2020)$

31. Kaczmarek, L. D. et al. High-approach and low-approach positive affect influence physiological responses to threat and anger. Int. J. Psychophysiol. 138, 27-37. https://doi.org/10.1016/j.ijpsycho.2019.01.008 (2019).

32. Kosakowski, M. The effect of emodiversity on cardiovascular responses during the interpersonal limited resources conflict. Examinations of affective states and traits within the framework of polyvagal theory. Unpublished doctoral dissertation. (Adam Mickiewicz University, 2021).

33. Kaczmarek, L.D., et al. Positive emotions boost enthusiastic responsiveness to capitalization attempts. Dissecting self-report, physiology, and behavior (under review).

34. Beatty, G. F., Cranley, N. M., Carnaby, G. \& Janelle, C. M. Emotions predictably modify response times in the initiation of human motor actions: A meta-analytic review. Emotion 16, 237-251. https://doi.org/10.1037/emo0000115 (2016).

35. Harmon-Jones, E., Gable, P. A. \& Price, T. F. Leaning embodies desire: Evidence that leaning forward increases relative left frontal cortical activation to appetitive stimuli. Biol. Psychol. 87, 311-313. https://doi.org/10.1016/j.biopsycho.2011.03.009 (2011).

36. Eijckelhof, B. H. W. et al. The effects of workplace stressors on muscle activity in the neck-shoulder and forearm muscles during computer work: A systematic review and meta-analysis. Eur. J. Appl. Physiol. 113, 2897-2912. https://doi.org/10.1007/s00421-0132602-2 (2013).

37. Campos, B. et al. What is shared, what is different? Core relational themes and expressive displays of eight positive emotions. Cogn. Emot. 27, 37-52. https://doi.org/10.1080/02699931.2012.683852 (2013).

38. Cowen, A. S. \& Keltner, D. Self-report captures 27 distinct categories of emotion bridged by continuous gradients. Proc. Natl. A Sci. 114, E7900-E7909. https://doi.org/10.1073/pnas.1702247114 (2017).

39. Hewig, J. et al. Brief Report: A revised film set for the induction of basic emotions. Cogn. Emot. 19, 1095-1109. https://doi.org/10. 1080/02699930541000084 (2005).

40. Kaczmarek, L. D. et al. Splitting the affective atom: Divergence of valence and approach-avoidance motivation during a dynamic emotional experience. Curr. Psychol. https://doi.org/10.1007/s12144-019-00264-3 (2019).

41. Gross, J. J. \& Levenson, R. W. Emotion elicitation using films. Cogn. Emot. 9, 87-108. https://doi.org/10.1080/026999395084089 66 (1995).

42. Schaefer, A., Nils, F., Sanchez, X. \& Philippot, P. Assessing the effectiveness of a large database of emotion-eliciting films: A new tool for emotion researchers. Cogn. Emot. 24, 1153-1172. https://doi.org/10.1080/02699930903274322 (2010).

43. Marchewka, A., Żurawski, Ł, Jednoróg, K. \& Grabowska, A. The Nencki Affective Picture System (NAPS): Introduction to a novel, standardized, wide-range, high-quality, realistic picture database. Behav. Res. Methods. 46, 596-610. https://doi.org/10. 3758/s13428-013-0379-1 (2014).

44. Kaczmarek, L. D. et al. Give and take: The role of reciprocity in capitalization. J. Posit. Psychol. https://doi.org/10.1080/17439760. 2021.1885054 (2021)

45. Kaczmarek, L. D. et al. Effects of emotions on Heart Rate Asymmetry. Psychophysiology 56, e13318. https://doi.org/10.1111/psyp. 13318 (2019).

46. McGinley, J. J. \& Friedman, B. H. Autonomic specificity in emotion: The induction method matters. Int. J. Psychophysiol. 118, 48-57. https://doi.org/10.1016/j.ijpsycho.2017.06.002 (2017).

47. Stephens, C. L., Christie, I. C. \& Friedman, B. H. Autonomic specificity of basic emotions: Evidence from pattern classification and cluster analysis. Biol. Psychol. 84, 463-473. https://doi.org/10.1016/j.biopsycho.2010.03.014 (2010).

48. Muthén, L. K. \& Muthen, B. Mplus user's guide: Statistical analysis with latent variables, user's guide (Author, 2017).

49. Muthén, B. Bayesian analysis in Mplus: A brief introduction (2010).

50. Van de Schoot, R. et al. A gentle introduction to Bayesian analysis: Applications to developmental research. Child Dev. 85, 842-860. https://doi.org/10.1111/cdev.12169 (2014).

51. Field, A. Discovering statistics using IBM SPSS statistics. Sage (2013).

\section{Acknowledgements}

The authors thank Michał Kosakowski, Jolanta Enko, Martyna Dziekan, and other Psychophysiology and Health Lab members at Adam Mickiewicz University for helping in data collection. The authors thank Katarzyna Janicka (katarzyna.janicka.kj@gmail.com) for creating Fig. 2. Preparation of this article was supported by the National 
Science Center (Poland) research grants (UMO-2017/25/N/HS6/00814; UMO-2012/05/B/HS6/00578; UMO2014/15/B/HS6/02418; UMO-2015/17/N/HS6/02794) and doctoral scholarship (UMO-2019/32/T/HS6/00039).

\section{Author contributions}

M.B. and L.D.K. designed research; M.B. analysed the results and wrote the main manuscript text; all authors interpreted the data and reviewed the manuscript.

\section{Competing interests}

The authors declare no competing interests.

\section{Additional information}

Supplementary Information The online version contains supplementary material available at https://doi.org/ 10.1038/s41598-021-86841-8.

Correspondence and requests for materials should be addressed to M.B.

Reprints and permissions information is available at www.nature.com/reprints.

Publisher's note Springer Nature remains neutral with regard to jurisdictional claims in published maps and institutional affiliations.

Open Access This article is licensed under a Creative Commons Attribution 4.0 International License, which permits use, sharing, adaptation, distribution and reproduction in any medium or format, as long as you give appropriate credit to the original author(s) and the source, provide a link to the Creative Commons licence, and indicate if changes were made. The images or other third party material in this article are included in the article's Creative Commons licence, unless indicated otherwise in a credit line to the material. If material is not included in the article's Creative Commons licence and your intended use is not permitted by statutory regulation or exceeds the permitted use, you will need to obtain permission directly from the copyright holder. To view a copy of this licence, visit http://creativecommons.org/licenses/by/4.0/.

(C) The Author(s) 2021 